\title{
VARIATION IN PASTEURELLA PNEUMOTROPICA
}

\author{
A. Hooper and A. Sebesteny \\ Animal Health Unit, Imperial Cancer Research Fund, Lincoln's Inn Fields, \\ London, WC2A 3PX
}

PASTEURELla PNEUMotropica (Jawetz, 1950) is recognised as an important pathogen of rodents, but it may also affect other species and has even been isolated from the human throat (Henriksen, 1962). It is often regarded as an organism with well-defined main characteristics: Gram-negative rods or cocco-bacilli that are non-motile, non-haemolytic, oxidase, catalase, urease, and indole positive, and that ferment glucose, sucrose, and maltose, but not mannitol, without the production of gas. Recently, in studies made at the University of Surrey (Brown and Smith, 1972), at the Medical Research Council Laboratory Animals Centre, Carshalton, Surrey, and by ourselves, a number of deviations from the usual pattern have been observed.

This paper reports the isolation of a strain of $P$. pneumotropica, which on subsequent subculture produced a proportion of a haemolytic, white-coloured-colony variant that did not revert to the wild type.

\section{MATERIALS AND METHODS}

The $P$. pneumotropica isolates came from specimens from laboratory rodents, mainly rats and mice, bred and maintained at the Imperial Cancer Research Fund (ICRF) Laboratories and at breeding and research establishments within the Laboratory Animals Centre Accreditation Scheme (Townsend, 1969). The specimens were swabs taken from the nasopharynx of healthy rodents selected at random and killed, and swabs or tissues from a wide range of organs or sites affected with inflammatory or purulent lesions in dead or killed sick animals.

Four isolates, which produced the haemolytic variant described here, originated from mouth swabs taken from a batch of four live rats with malformed teeth.

Primary isolation and subsequent subcultures were made on blood agar incubated aerobically at $37^{\circ} \mathrm{C}$ : the medium comprised a layer of Oxoid Blood Agar Base no. 2 (CM 271) with $7 \%$ horse blood over a layer of the same base agar. Eight $P$. pneumotropica isolates from the ICRF Laboratories and 20 from the Laboratory Animal Centre were exchanged and examined by both laboratories to confirm the atypical reaction and to observe the extent of discrepancy in the results of biochemical tests arising from differences in technique or interpretation. No deliberate attempt was made to standardise materials and methods in the two laboratories, the organisms being treated in the routine of the respective laboratory.

Both laboratories observed reactions in commercially available carbohydrate media incubated at $37^{\circ} \mathrm{C}$ for up to 1 week. Carbohydrate media were based on Andrade Peptone Water in ready-to-use or in tablet form, as available. These included Oxoid R53, 57, 58, 59, 68, 69, 70, 72, 75; CM62 tablets, with added SR10, 11, 12, 13, 14, 15 and 17, or with Analar or Koch-Light carbohydrates; and Southern Group Laboratories 0517 A, B, C, D, E, H, I, $\mathrm{J}, \mathrm{K}, \mathrm{L}, \mathrm{M}, \mathrm{N}, \mathrm{O}, \mathrm{P}, \mathrm{R}$ and $\mathrm{U}$. Both laboratories experienced difficulty in obtaining some of these materials, and this resulted in the occasional omission of more rarely used carbohydrates.

At 24-hour intervals up to 5 days, tests were made with Kovács' reagent for the production of indole in cultures grown in Peptone Water (Oxoid R4), Tryptone Water (Oxoid CM88), Nutrient Broth (Oxoid R1 or CM68), and in Nutrient Broth with $10 \%$ added Tryptone Water. Urea Agar (Oxoid R3 or Southern Group 05665) was used for the detection of urease. The oxidase test was that of Kovács as described by Cowan and Steel (1966). 
Antigens for the production of antisera were prepared from growth of the test organisms streaked in a cross-hatched manner on $7 \%$ blood-agar plates which had been incubated aerobically for 24 hours at $37^{\circ} \mathrm{C}$. A killed suspension of the growth corresponding in opacity to Brown's tube no. 6 was prepared in $0.25 \%$ formol saline. A proportion was mixed with an equal amount of Freund's incomplete adjuvant for the initial injection, while the rest was diluted to an opacity corresponding to Brown's tube no. 4.

\section{TABLE}

Cultural characters of a typical ICRF strain of P. pneumotropica, and of the wild-type isolate, and the haemolytic variant of it

\begin{tabular}{|c|c|c|c|}
\hline \multirow[b]{2}{*}{ Character } & \multicolumn{3}{|c|}{ Reactions obtained with } \\
\hline & $\begin{array}{l}\text { a typical } \\
\text { ICRF strain }\end{array}$ & $\begin{array}{l}\text { the wild-type } \\
\text { strain }\end{array}$ & $\begin{array}{l}\text { the variant of } \\
\text { the wild-type } \\
\text { strain }\end{array}$ \\
\hline $\begin{array}{l}\text { Colour of colony } \\
\text { Haemolysis } \\
\text { Production of: } \\
\text { oxidase } \\
\text { urease } \\
\text { indole } \\
\text { Production of acid* but no } \\
\text { gas from: } \\
\text { glucose } \\
\text { lactose } \\
\text { sucrose } \\
\text { mannitol } \\
\text { maltose } \\
\text { raffinose } \\
\text { trehalose } \\
\text { dulcitol } \\
\text { salicin } \\
\text { sorbitol } \\
\text { adonitol } \\
\text { inositol } \\
\text { xylose } \\
\text { arabinose } \\
\text { inulin } \\
\text { dextrin }\end{array}$ & $\begin{array}{c}\text { faintly yellow } \\
- \\
(+) \\
+ \\
+ \\
+ \\
+ \text { or }- \\
+ \\
+ \\
+ \\
+ \\
+ \\
- \\
= \\
= \\
+ \\
+ \\
+ \\
\ldots \\
\ldots\end{array}$ & 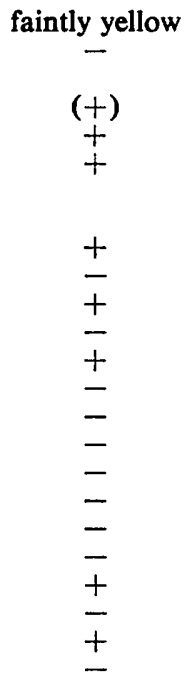 & $\begin{array}{l}\frac{+}{+} \\
+ \\
\frac{+}{+} \\
+ \\
+ \\
+ \\
- \\
- \\
- \\
\pm \\
+ \\
+\end{array}$ \\
\hline
\end{tabular}

* Within 7 days.

$+=$ Positive reaction; $-=$ negative reaction; $++=$ positive oxidase reaction in $5 \mathrm{~s}$; $(+)=$ positive oxidase reaction in $30 \mathrm{~s} ; \ldots=$ not tested.

The antisera were prepared in adult rabbits. Ten initial subcutaneous injections, each of $0.1 \mathrm{ml}$ of the antigen-adjuvant mixture were distributed along the shaved back of each animal. Two weeks later, an intravenous injection of $0.2 \mathrm{ml}$ of the diluted antigen alone was given, followed by five intravenous injections of $0.5 \mathrm{ml}$ at 3- to 4-day intervals. One week after the last injection the rabbits were exsanguinated. The resulting antisera were used for slideagglutination tests.

\section{RESULTS}

\section{Comparative trial}

We have studied 28 strains of $P$. pneumotropica in parallel with the bacteriological laboratory at the Laboratory Animals Centre performing up to 15 fermentation reactions for each strain. Of the total 358 fermentation tests performed by each laboratory, $273(76.5 \%)$ gave 
conforming results, $65(18.2 \%)$ gave uncertain results in one of the laboratories and $20(5 \cdot 6 \%)$ gave contradictory results.

On the other hand, the study revealed the following atypical reactions in both laboratories: negative catalase reaction (one strain), gas production in maltose (one strain), mannitol fermentation (one strain), negative indole reaction in all media (13 strains), and weak indole reaction (one strain).

\section{The variant}

On blood agar, colonies of the atypical isolates from mouth swabs of rats appeared identical to the faintly yellow, translucent colonies of typical $P$. pneumotropica. They also possessed the characteristic " musty" odour of this organism, and were slide agglutinated by antiserum prepared against a typical ICRF strain of $\boldsymbol{P}$. pneumotropica. On subsequent subculture on blood agar, colonies of the wild type were mixed with a proportion of colonies of a haemolytic variant after 24 hours' aerobic incubation at $37^{\circ} \mathrm{C}$. During five subsequent subcultures, single colonies of this variant consistently yielded only colonies of the same type whilst single colonies of the wild type yielded both types of colony in somewhat variable proportions.

Colonies of the variant were easily distinguished macroscopically by their clearly demarcated zone of beta haemolysis, $0.5 \mathrm{~mm}$ wide, after $24-72$ hours' aerobic incubation at $37^{\circ} \mathrm{C}$. In addition, they were much whiter than the faintly yellow typical strains. Microscopically, the cocco-bacilli of the haemolytic variant appeared slightly larger than those of the wild type.

The table shows some characteristics of both the wild type and the variant in comparison with a typical strain of $\boldsymbol{P}$. pneumotropica of the kind most frequently isolated from ICRF mice and rats. Biochemically, the wild type and the variant differed in three of the 16 carbohydrate fermentations tested: the variant acidified raffinose, trehalose and dulcitol, but the wild type did not. A further biochemical difference was the failure of the haemolytic variant to produce indole in any of the media, even after 5 days' incubation. Its oxidase reaction was also more rapid and intense (positive in $5 \mathrm{~s}$ ) than that of the wild type (positive in $30 \mathrm{~s}$ ). Antiserum prepared against a typical ICRF strain of $\boldsymbol{P}$. pneumotropica gave positive slideagglutination reactions with both the wild type and its haemolytic variant.

\section{DisCUSSION}

The first indication that variants of $P$. pneumotropica might exist came from Heyl (1963), who described 52 isolates of $P$. pneumotropica that consistently failed to acidify inositol, but acidified xylose; for these he proposed the name $P$. pneumotropica var. xylophila. The cultures originally described by Jawetz (1950) failed to acidify xylose but acidified inositol, and these Heyl (1963) termed $P$. pneumotropica var. pneumotropica. The difficulty of subdividing the species into biotypes based on biochemical differences was referred to by Henriksen (1962), who found that fermentation reaction in conventional media were faint and difficult to read.

In the comparative studies of 28 strains of $\boldsymbol{P}$. pneumotropica with the Laboratory Animals Centre, tests of inositol and xylose fermentation each contributed one contradictory result, together with a total of 14 uncertain results; the results of 35 tests were in agreement. The indole reaction also created problems. It was often negative after 1 day, turning faintly positive later. On occasion it appeared negative in peptone or tryptone water because growth was poor or absent but positive in nutrient broth with $10 \%$ added tryptone water.

The uncertain interpretation of these biochemical tests cannot be ignored, but this study also revealed several corroborated atypical reactions, such as a negative catalase test, gas production in maltose, mannitol fermentation, and absence of indole production in any medium. One of the indole-negative strains caused the "breakdown" of the specifiedpathogen-free animal unit of the Laboratory Animals Centre (Blackmore, 1972).

One way in which deviations from the normal characteristics attributed to $P$.pneumotropica may arise is clearly demonstrated by our observation of the emergence of a variant with a set of atypical reactions during laboratory subculture of an apparently typical $\boldsymbol{P}$. pneumotropica. 


\section{SUMMARY}

Of 358 carbohydrate tests carried out independently by two diagnostic laboratories on 28 Pasteurella pneumotropica isolates, the results of 273 were in agreement, 65 were judged uncertain by one laboratory, and 20 were contradictory. On the other hand, the following corroborated atypical reactions were found: negative catalase reaction (one strain), gas production in maltose (one strain), acid production in mannitol (one strain), and weak or absent indole production (14 strains).

A strain of $\boldsymbol{P}$. pneumotropica from rats produced on subculture typical colonies together with a proportion of white, beta-haemolytic colonies of a variant that was indole negative, gave a stronger oxidase reaction, and acidified raffinose, trehalose and dulcitol, in addition to the carbohydrates acidified by the wild type.

We wish to thank Miss A. Hill and Dr D. K. Blackmore of the Laboratory Animal Centre, Carshalton, for their collaboration in the comparative studies, Professor J. E. Smith of the University of Surrey for advice, and Miss J. Murkin for technical assistance.

\section{REFERENCES}

BLACKMORE, D. K. 1972. Accidental contamination of a specified-pathogen-free-unit. Lab. Anims, 6, 257.

Brown, J. A. AND Smith, J. E. 1972. Personal Communication.

Cowan, S. T. AND Steel, K. J. 1966. Manual for the identification of medical bacteria. Cambridge, p. 150.

HENRIKSEN, S. D. 1962. Some pasteurella strains from the human respiratory tract-a correction and supplement. Acta path. microbiol. scand., 55, 355.

HeYL, J. G. 1963. A study of Pasteurella strains from animal sources. Antonie van Leeuwenhoek, $29,79$.

JAWETZ, E. 1950. A pneumotropic pasteurella of laboratory animals. I. Bacteriological and serological characteristics of the organism. J. Infect. Dis., 86, 173.

TownsEND, G. H. 1969. The grading of commercially-bred laboratory animals. Vet. Rec., 85, 225. 